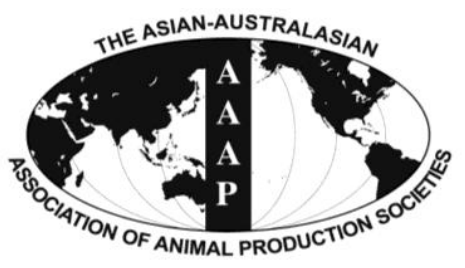

Asian-Aust. J. Anim. Sci.

Vol. 25, No. $10: 1351$ - 1356

October 2012

www.ajas.info

http://dx.doi.org/10.5713/ajas.2012.12162

\title{
Comparison of Growth Performance of Antibiotic-free Yorkshire Crossbreds Sired by Berkshire, Large Black, and Tamworth Breeds Raised in Hoop Structures
}

\author{
N. Whitley, W. E. M. Morrow ${ }^{1}$, M. T. See ${ }^{1}$ and S.-H. Oh* \\ North Carolina A\&T State University, Greensboro, North Carolina, USA
}

\begin{abstract}
The objective of this study was to compare body weight, ADG, and feed:gain ratio of antibiotic-free pigs from Yorkshire dams and sired by Yorkshire (YY), Berkshire (BY), Large Black (LBY) or Tamworth (TY) boars. All the crossbred pigs in each of three trials were raised as one group from weaning to finishing in the same deep-bedded hoop, providing a comfortable environment for the animals which allowed rooting and other natural behaviors. Birth, weaning and litter weights were measured and recorded. From approximately $50 \mathrm{~kg}$ to market weight $(125 \mathrm{~kg}$ ), feed intake and body weights were recorded manually (body weight) or using a FIRE (Feed Intake Recording Equipment, Osborne Industries Inc. Osborne, Kansas) system with eight individual feeding stations. Feed intake data for 106 finishing pigs between 140 and $210 \mathrm{~d}$ of age and the resulting weights and feed conversion ratios were analyzed by breed type. Least square means for body weights (birth, weaning and to $240 \mathrm{~d}$ ) were estimated with Proc Mixed in SAS 9.2 for fixed effects such as crossbreed and days of age within the sire breed. The differences within fixed effects were compared using least significant differences with DIFF option. Individual birth weights and weaning weights were influenced by sire breed $(\mathrm{p}<0.05)$. For birth weight, BY pigs were the lightest, TY and YY pigs were the heaviest but similar to each other and LBY pigs were intermediate. For weaning weights, BY and LBY pigs were heavier than TY and YY pigs. However, litter birth and weaning weights were not influenced by sire breed, and average daily gain was also not significantly different among breed types. Tamworth sired pigs had lower overall body weight gain, and feed conversion was lower in TY and YY groups than BY and LBY groups ( $<<0.05$ ), however, number of observations was somewhat limited for feed conversion and for Tamworth pigs. Overall, no convincing differences among breed types were noted for this study, but growth performance in the outdoor environment was satisfactory. (Key Words: Berkshire, Large Black, Tamworth, Antibiotic-free Yorkshire, Crossbred, Growth)
\end{abstract}

\section{INTRODUCTION}

In recent years, food safety issues and human health concerns have been raised regarding excessive medication of animals in confined management systems and possible links to antibiotic resistance. In addition, animal welfare has long been a concern for pork producers and, more recently, for consumers. Conventional confinement pork production systems are often criticized on the grounds of animal welfare and environmental impacts. In response, new markets have emerged for animal-compassionate and alternative pork production. Several wholesale buyers are offering United States growers twice the current market price to supply this demand (personal communication with

\footnotetext{
* Corresponding Author: S.-H. Oh. Tel: +1-336-334-7672, Fax: +1-336-334-7288, E-mail: soh@ncat.edu

${ }^{1}$ North Carolina State University, Raleigh, North Carolina, USA. Submitted Mar. 27, 2012; Accepted Jul. 1, 2012; Revised Jul. 9, 2012
}

local farmers in North Carolina), which indicates an important opportunity for small-scale, limited resource farmers.

There has been a resurgence in interest in outdoor pig production recently (Thornton, 1990; Honeyman, 2005), and concerns about the lost productivity of sows and pigs raised outdoors have declined (Kleinbeck and McGlone, 1999). One of the concerns with outdoor systems is that there is less control over the production environment which may adversely affect animal performance, especially in regions with hot and humid climates. Alternative production systems, including pasture-based huts and deep-bedded hoop barns have the potential to address animal welfare, food safety and some environmental concerns, as well as provide new opportunities for small, limited resource farmers.

An important question that needs to be addressed is which genotypes (breeds) are best fitted to the outdoor 
system (Kleinbeck and McGlone, 1999). There is anecdotal evidence to suggest that some breeds of pigs perform "better" in an outdoor system than others, but there are few scientific studies regarding which breeds or lines of pigs actually excel in outdoor production facilities. Dark breeds such as Tamworth are said to be more sustainable for the outdoor system (Gegner, 2001). The Tamworth breed has been used in the past for prolificacy and milking ability (McPhee, 1931; Winters et al., 1943).

It is also important to make alternative swine production systems more marketable to upscale consumers (Gegner, 2004). Market opportunities for rare breeds such as Large Black are beginning to increase, and farmers need information on growth patterns of different breeds. The Berkshire breed, known for its meat quality when raised in confinement systems (Suzuki et al., 2003; Aziz, 2004), might be a good candidate for alternative production systems. It has been reported that about 28,000 dams are bred in Japan, and the retail price of purebred Berkshire is $50 \%$ more expensive than regular finishing pigs (Suzuki et al., 2003). However, there are few studies involving performance tests of crossbred pigs reared in alternative production systems, in part because of difficulties with measuring body weights and feed intake on site. However, Young and Lawrence (1994) have reported successful use of the FIRE system. The FIRE system is used to evaluate feed intake, feeding time, feeding rate, feed conversion, and number of feedings per day. It can be adapted to use in a group-fed, hoop-house type operation by utilizing a feed trough weighed by a load cell and the placement of an electronic transponder in the ear of the animals (Casey, 2003).

The objective of this study was to investigate the growth characteristics of antibiotic-free Yorkshire crossbred pigs sired by Berkshire, Large Black and/or Tamworth raised in a hoop facility, which was aimed to track the growth patterns during the finishing phase.

\section{MATERIALS AND METHODS}

The experiments were performed at the Center for Environmental Farming Systems (CEFS)/Cherry Research Station of the North Carolina Department of Agriculture and Consumer Services, and at the University Farm of North Carolina Agricultural and Technical State University (NCA\&T). The CEFS Alternative Swine Unit is located in Goldsboro (latitude $+35^{\circ} 23^{\prime} 26.82^{\prime \prime}$, longitude $-78^{\circ} 1^{\prime}$ $43.76^{\prime \prime}$ ), and the NCA\&T farm is in Greensboro (latitude $+36^{\circ} 4^{\prime} 16.63^{\prime \prime}$, longitude $-79^{\circ} 43^{\prime} 33.02^{\prime \prime}$ ). Both NC cities feature a humid subtropical climate (Köppen climate classification; Lohmann et al., 1993), with subtropical summer temperatures and mild winters, and average annual precipitation of about $110 \mathrm{~cm}$.
The CEFS unit has been raising antibiotic-free Yorkshire sows in hoop structures for more than $10 \mathrm{yrs}$. For Trial 1, 24 gilts approximately 6 months of age were moved from CEFS to NCA\&T. For Trial 2 and 3, fifty-four gilts total (the 24 at NCA\&T; 30 at CEFS) were artificially bred with the semen of Berkshire (BY), Large Black (LBY), Tamworth (TY) or Yorkshire (YY; control) boars with 10 sows bred per sire breed at CEFS and 8 sows bred per sire breed at NCA\&T. The same sows were used for each trial with sire breed randomly chosen each time. All sows were estrus synchronized with Matrix ${ }^{\circledR}$ as per the manufacturer directions prior to breeding. The number of litters or animals in each trial are provided in Table 1.

Sows were farrowed in a hoop structure. Pigs were castrated within a week and weaned when the youngest litter was 4 wks old. Farrowing for Trials 1, 2 and 3 occurred in May and October 2009, and April, 2010, respectively. All pigs in each trial for each farm were raised as one group in a deep-bedded hoop $(16 \mathrm{~m} \times 32 \mathrm{~m})$ from weaning through to finishing. The deep bedding, straw, corn stalks, or hay, was spread approximately 35 to $45 \mathrm{~cm}$ thick whenever needed and provided a comfortable environment for the animals, which allowed rooting and other natural behaviors.

\section{Birth and weaning weight}

For Trial 2 and 3 and at NCA\&T only, body weights were recorded on the day after birth (Table 1). Sire breed and trial were included in the statistical model for analysis. Weaning weights were recorded for all trials (Table 1). PROC GLM was used to analyze the data (SAS 9.2), and location, sire breed, and trial were included in the statistical model as fixed effects. For all analyses, non-significant interactions were excluded from the final model. Least square means were estimated to compare the level of each effect with the pdiff option.

\section{Body weight, feed:gain and ADG}

Body weights were measured manually in both locations approximately every $30 \mathrm{~d}$ beginning at around 60 $\mathrm{d}$ of age and up to $240 \mathrm{~d}$ of age; weights were adjusted for common days of age $(60,90,120$, etc.) by multiplying actual ADG for each pig by the common day of age, rounding to the nearest $15 \mathrm{~d}$ of age for the common day of age (i.e. for pigs that were $70 \mathrm{~d}$ of age at weighing, weights were adjusted to $60 \mathrm{~d}$ of age). A FIRE (Feed Intake Recording Equipment, Osborne Industries Inc. Osborne, Kansas) system with 8 feeding stations was used at NCA\&T. Body weights and daily feed intake for 106 finishing pigs were recorded from March to November, 2010 at NCA\&T (from approximately 140 to $210 \mathrm{~d}$ of age for Trial 2 and 3) using the FIRE system, resulting in 101,394 observations. Data was eliminated before analysis if feed intake per visit 
Table 1. Number of animals or litters of four different breed types weighed at two locations in three outdoor trials*

\begin{tabular}{|c|c|c|c|c|c|c|c|c|}
\hline & & \multicolumn{2}{|c|}{ Trial 1} & \multicolumn{2}{|c|}{ Trial 2} & \multicolumn{2}{|c|}{ Trial 3} & \multirow{2}{*}{ Total } \\
\hline & & CEFS & NCA\&T & CEFS & NCA\&T & CEFS & NCA\&T & \\
\hline \multirow[t]{6}{*}{$\mathrm{BY}$} & IBW & - & - & - & 61 & - & 41 & 102 \\
\hline & LBW & - & - & - & 8 & - & 4 & 12 \\
\hline & IWW & - & 28 & 25 & 42 & 42 & 36 & 173 \\
\hline & LWW & - & 7 & 5 & 8 & 6 & 4 & 30 \\
\hline & BWM & - & 28 & 25 & 28 & 24 & - & 105 \\
\hline & BWF & - & - & - & 28 & - & 23 & 51 \\
\hline \multirow[t]{6}{*}{ LBY } & IBW & - & - & - & 53 & - & - & 53 \\
\hline & LBW & - & - & - & 7 & - & - & 7 \\
\hline & IWW & - & 26 & 21 & 28 & - & - & 75 \\
\hline & LWW & - & 4 & 2 & 6 & - & - & 12 \\
\hline & BWM & - & 26 & 21 & 28 & - & - & 75 \\
\hline & BWF & - & - & - & 27 & - & - & 27 \\
\hline \multirow[t]{6}{*}{ TY } & IBW & - & - & - & - & - & 39 & 39 \\
\hline & LBW & - & - & - & - & - & 4 & 4 \\
\hline & IWW & - & - & - & - & 16 & 19 & 35 \\
\hline & LWW & - & - & - & - & 2 & 3 & 5 \\
\hline & BWM & - & - & - & - & 16 & - & 16 \\
\hline & BWF & - & - & - & - & - & 12 & 12 \\
\hline \multirow[t]{6}{*}{ YY } & IBW & - & - & - & 59 & - & 30 & 89 \\
\hline & LBW & - & - & - & 6 & - & 3 & 9 \\
\hline & IWW & - & 29 & 22 & 35 & 33 & 21 & 140 \\
\hline & LWW & - & 7 & 4 & 6 & 5 & 3 & 25 \\
\hline & BWM & - & 29 & 22 & 7 & 25 & - & 83 \\
\hline & BWF & - & - & - & 7 & - & 8 & 15 \\
\hline \multirow[t]{6}{*}{ Total } & IBW & - & - & - & 173 & - & 110 & 283 \\
\hline & LBW & - & - & - & 21 & - & 11 & 32 \\
\hline & IWW & - & 83 & 68 & 105 & 91 & 76 & 423 \\
\hline & LWW & - & 18 & 11 & 20 & 13 & 10 & 72 \\
\hline & BWM & - & 83 & 68 & 63 & 65 & - & 279 \\
\hline & BWF & - & - & - & 63 & - & 43 & 106 \\
\hline
\end{tabular}

* Weights collected included: IBW = Individual birth weight; LBW = Litter birth weight; IWW = Individual weaning weight; LWW = Litter weaning weight; BWM = Body weight collected manually; BWF = Body weight collected by a FIRE system. Locations were the Cherry Research Farm, Center for Environmental Farming System (CEFS) alternative swine unit and North Carolina A\&T State University (NCA\&T) farm. Breed types were Berkshire $\times$ Yorkshire (BY); Large Black $\times$ Yorkshire (LBY); Tamworth $\times$ Yorkshire (TY) and Yorkshire $\times$ Yorkshire (YY).

was greater than $2 \mathrm{~kg}$ (Casey and Dekkers, 2001). The complete feed intake record for each pig was then evaluated for outliers by plotting feed intake by day and testing each feed intake observation with the Cook's D test statistic. Outliers were removed based on the values from the equation of Cook's $D$ that were greater than $4 / n$, where $n$ is the number of observations (Cook and Weisberg, 1982). After removal of outliers, 86,067 daily feed intake and body weight records were utilized in the subsequent analysis (Table 2). This data was used to compare growth performance among breed types including growth pattern, feed:gain ratio, and ADG. Least square means of body weight were estimated with Proc Mixed in SAS 9.2 for fixed effects such as breed type and days of age within the sire breed. The differences within fixed effects were compared using least square means with a DIFF option.

For the adjusted body weight data collected manually in both locations, the same factors described above were included as fixed effects in the statistical model using Proc Mixed in SAS 9.2. The effects of trial, location, and interactions were not significant and were thus not included in the final model.

\section{RESULTS AND DISCUSSION}

\section{Birth and weaning weight}

For individual birth weights, there was an effect of breed $(\mathrm{p}<0.05)$ in which BY pigs were the lightest $(\mathrm{p}<0.05$; 
Table 2. Number of animals of four different breed types raised outdoors in two locations and three trials for which body weight was recorded manually (BWM) or by a FIRE ${ }^{\circledR}$ system (BWF)*

\begin{tabular}{|c|c|c|c|c|c|c|c|c|}
\hline & & \multicolumn{2}{|c|}{ Trial 1} & \multicolumn{2}{|c|}{ Trial 2} & \multicolumn{2}{|c|}{ Trial 3} & \multirow{2}{*}{ Total } \\
\hline & & CEFS & NCA\&T & CEFS & NCA\&T & CEFS & NCA\&T & \\
\hline \multirow[t]{2}{*}{$\mathrm{BY}$} & BWM & - & 160 & 125 & 110 & 120 & - & 515 \\
\hline & BWF & - & - & - & 39,885 & - & 7,960 & 47,845 \\
\hline \multirow[t]{2}{*}{ LBY } & BWM & - & 152 & 105 & 105 & - & - & 362 \\
\hline & BWF & - & - & - & 22,601 & - & - & 22,601 \\
\hline \multirow[t]{2}{*}{ TY } & BWM & - & - & - & - & 80 & - & 80 \\
\hline & BWF & - & - & - & - & - & 3,628 & 3,628 \\
\hline \multirow[t]{2}{*}{ YY } & BWM & - & 165 & 110 & 26 & 125 & - & 426 \\
\hline & BWF & - & - & - & 8,998 & - & 2,995 & 11,993 \\
\hline \multirow[t]{2}{*}{ Total } & BWM & - & 477 & 340 & 241 & 325 & - & 1383 \\
\hline & BWF & - & - & - & 71,484 & - & 14,583 & 86,067 \\
\hline
\end{tabular}

* Breed types were Berkshire $\times$ Yorkshire (BY); Large Black $\times$ Yorkshire (LBY); Tamworth $\times$ Yorkshire (TY) and Yorkshire $\times$ Yorkshire (YY). Locations were the Cherry Research Farm, Center for Environmental Farming System (CEFS) alternative swine unit and North Carolina A\&T State University (NCA\&TSU) farm.

$1.34 \pm 0.03 \mathrm{~kg})$, TY $(1.49 \pm 0.05 \mathrm{~kg})$ and $\mathrm{YY}(1.42 \pm 0.03 \mathrm{~kg})$ pigs were the heaviest but similar to each other and LBY pigs were intermediate $(1.40 \pm 0.04 \mathrm{~kg})$. However, litter birth weights were not influenced by sire breed, indicating that differences in individual birth weights were likely a reflection of litter size. However, because total number of litters per breed was limited, additional research would be beneficial. Individual $(0.95 \pm 0.02$ and $1.87 \pm 0.03 \mathrm{~kg})$ and litter birth weights $(7.86 \pm 0.81$ and $18.56 \pm 0.98 \mathrm{~kg})$ were significantly different $(\mathrm{p}<0.05)$ between Trials 2 and 3 , respectively. The warmer weather typically seen in April (Trial 3) compared to October (Trial 2) may have contributed in part to the higher birth weights seen in Trial 3. Similarly, in a cooperative study with 999 litters from seven southern states (including North Carolina), pigs born in the warm season were heavier at birth than those born in the cool season (Coffey et al., 1994).

The effects of sire breed and trial were significant for individual weaning weights $(\mathrm{p}<0.05)$. The BY and LBY pigs were heavier than TY and YY pigs $(7.76 \pm 0.15,8.07 \pm$ $0.22,6.40 \pm 0.34$ and $6.76 \pm 0.16 \mathrm{~kg}$, respectively). The IWW for the first trial $(6.32 \pm 0.24 \mathrm{~kg})$ were significantly $(\mathrm{p}<0.05)$ lower than those in Trial $2(7.89 \pm 0.16 \mathrm{~kg})$ and $3(7.54 \pm 0.15$ $\mathrm{kg})$. However, IWW were similar for CEFS $(7.36 \pm 0.18 \mathrm{~kg})$ and NCA\&T $(8.13 \pm 0.13 \mathrm{~kg})$.

For litter weaning weights, as with litter birth weights, there was no influence of sire breed, averaging $44.64 \pm 3.97$, $55.36 \pm 6.55,32.17 \pm 10.36$ and $38.13 \pm 4.27 \mathrm{~kg}$ for BY, LBY, TY and YY, respectively. The LWW were lightest for Trial $1(28.19 \pm 6.45 \mathrm{~kg})$, heavier for Trial $2(42.61 \pm 4.71 \mathrm{~kg})$ than Trial 1 and were the heaviest for Trial $3(56.93 \pm 4.69 \mathrm{~kg})$ $(\mathrm{p}<0.05)$. Location LWW were similar, averaging 38.28 \pm $5.39 \mathrm{~kg}$ for CEFS and $46.87 \pm 3.54 \mathrm{~kg}$ for NCA\&T. Gilts were used for Trial 1 and the same animals were used for
Trial 2 and 3, so the age and parity of most of the females used naturally increased with trial, making it expected that weaning weights would also increase with trial. An increase in gain from birth to weaning over three parities was also noted for a collaborative study of 999 litters from seven southern U.S. states, including North Carolina (Coffey et al., 1994).

\section{Body weight, ADG, and feed:gain}

Tamworth sired pigs, included only in Trial 3, had fewer animal records than the other breed types, therefore, the estimates were very limited compared to other groups. Overall, the LBY group was heavier $(p<0.05)$ than other groups for the FIRE system (Figure 1) and were also heavier $(p<0.05)$ for adjusted manual weight measurements from 90 to $240 \mathrm{~d}$ of age (Table 3). However, average daily gain (from 140 to $210 \mathrm{~d}$ of age) was not influenced by breed type $(0.79 \pm 0.03,0.80 \pm 0.04,0.97 \pm 0.09$ and $0.82 \pm 0.03 \mathrm{~kg} / \mathrm{d}$ for BY, LBY, TY and YY, respectively), and overall weight gain was not higher for LBY, indicating no actual benefit of LB sires over the other breeds (data for actual manual weights analyzed). As noted in the current study, no difference in ADG for breed type (Duroc sires with Tamworth, Tamworth $\times$ Landrace or Hampshire $\times$ Landrace sows) was noted in a previous outdoor versus confinement study conducted at North Carolina A\&T State University, though outdoor raised pigs grew 50\% faster than confinement raised pigs (Talbott et al., 2003).

Overall weight gain from 60 to $240 \mathrm{~d}$ of age was lowest for TY $(60.63 \pm 3.56 \mathrm{~kg})$ and similar for the other breed types $(72.51 \pm 1.48 \mathrm{~kg}$ for BY, $73.72 \pm 1.77 \mathrm{~kg}$ for LBY, and $71.00 \pm 1.69$ for $Y Y)$. Similarly, Tamworth $\times$ Berkshire pigs did not perform as well as Large Black $\times$ Berkshire pigs or other breed combinations for 112-d weight and age at market weight (Fahmy and Holtman, 1977). However, 


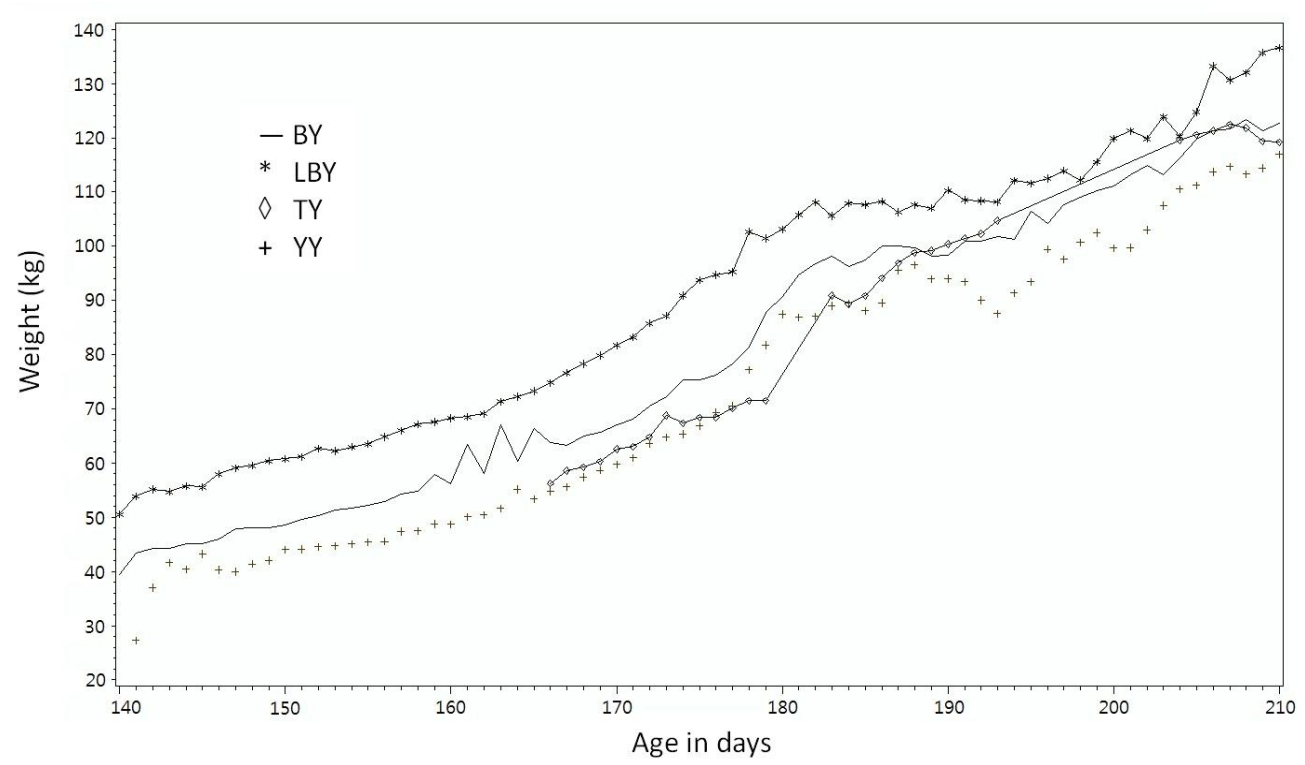

Figure 1. Least squares means of FIRE system body weights over time for different breed type pigs raised in an outdoor system. * Pig breed types were Berkshire $\times$ Yorkshire (BY), Large Black $\times$ Yorkshire (LBY), Tamworth $\times$ Yorkshire (TY) and Yorkshire $\times$ Yorkshire $(Y Y)$. Average SEM was $2.06 \mathrm{~kg}$ for BY, $2.81 \mathrm{~kg}$ for LBY, $4.27 \mathrm{~kg}$ for TY and $3.78 \mathrm{~kg}$ for YY.

again, in the present study, the numer of observations for Tamworth pigs was low (Table 1). In contrast to the present study, a study in the UK (Wood et al., 2004) noted that average daily gain for a $12 \mathrm{wk}$ period starting at $9 \mathrm{wks}$ of age was lower for Berkshire and Tamworth purebreds than for Large White pigs (similar to the Yorkshire breed).

The estimated growth curves for the FIRE system data among breeding groups in this study were linear. This result can be found in previous studies. Taylor and Hazel (1955) have reported growth from 135 to $174 \mathrm{~d}$ of age reflected in linear lines, and quadratic growth curves have been reported with a coefficient of the second degree polynomial lower than -0.005 (not meaningful), indicating that growth could be considered to have occurred in a linear fashion (Quijandria and Robison, 1971).

Using the FIRE system, it was found that TY and YY pigs were more feed efficient, with lower feed conversions $(p<0.05)$, than BY and LBY pigs based on the 106 animals from the FIRE system $(3.39 \pm 0.63,3.41 \pm 0.80,2.16 \pm 1.19$ and 2.46 \pm 1.07 for BY, LBY, TY and YY, respectively).
However, more observations would be needed to make any firm conclusions about differences in feed efficiency for these breed types.

In Japan, purebred Berkshire pigs had similar ADG $(0.78 \mathrm{~kg} / \mathrm{d})$ to that noted for the Berkshire sired pigs in the current study, but were not as feed efficient (4.87; Suzuki et al., 2003). However, in a North Carolina State University study using Berkshire-sired pigs from maternal-line females more similar to the animals in the current study, Berkshiresired pigs had a feed conversion closer to that of the current study (3.70 vs 3.39; Hasty et al., 2002).

Few recent scientific studies been conducted comparing differences in growth patterns and productivity in outdoor systems, likely due in part to the relative difficulty in measuring feed intake and growth rates for pigs raised in outdoor systems compared to confinement systems. Honeyman and Harmon (2003) compared performance of finishing pigs in hoop structures during winter and summer in Iowa, with summer weather closer to North Carolina weather than winter weather. Crossbred pigs from terminal

Table 3. Least squares means of body weights collected manually for four breed types of hogs raised in an outdoor system*

\begin{tabular}{lccrr}
\hline Days of age & BY & LBY & TY & YY \\
\hline 60 & $10.17 \pm 0.59^{\mathrm{a}}$ & $12.12 \pm 1.14^{\mathrm{a}}$ & $11.44 \pm 0.67^{\mathrm{a}}$ & $9.88 \pm 0.65^{\mathrm{a}}$ \\
90 & $25.86 \pm 0.99^{\mathrm{a}}$ & $31.79 \pm 2.40^{\mathrm{b}}$ & $25.92 \pm 1.23^{\mathrm{a}}$ & $25.23 \pm 1.14^{\mathrm{a}}$ \\
120 & $46.69 \pm 1.58^{\mathrm{a}}$ & $59.48 \pm 2.02^{\mathrm{b}}$ & $44.79 \pm 1.90^{\mathrm{a}}$ & $45.61 \pm 1.80^{\mathrm{a}}$ \\
150 & $73.53 \pm 2.19^{\mathrm{a}}$ & $88.06 \pm 2.57^{\mathrm{b}}$ & $70.92 \pm 2.64^{\mathrm{a}}$ & $72.38 \pm 2.46^{\mathrm{a}}$ \\
180 & $98.98 \pm 2.30^{\mathrm{a}}$ & $111.70 \pm 2.85^{\mathrm{b}}$ & $94.86 \pm 2.78^{\mathrm{a}}$ & $94.87 \pm 2.59^{\mathrm{a}}$ \\
210 & $115.48 \pm 2.07^{\mathrm{a}}$ & $130.78 \pm 2.94^{\mathrm{b}}$ & $109.36 \pm 2.42^{\mathrm{a}}$ & $113.37 \pm 2.34^{\mathrm{a}}$ \\
240 & $136.84 \pm 2.40^{\mathrm{a}}$ & $145.32 \pm 2.98^{\mathrm{b}}$ & $130.75 \pm 2.74^{\mathrm{a}}$ & $135.71 \pm 2.65^{\mathrm{a}}$ \\
\hline
\end{tabular}

* Breed types were Berkshire $\times$ Yorkshire (BY), Large Black $\times$ Yorkshire (LBY), Tamworth $\times$ Yorkshire (TY) and Yorkshire $\times$ Yorkshire (YY). Different superscripts differ among breed types, $\mathrm{p}<0.05$. 
Duroc boars with white breeds of sows were used in the experiments, and average daily gains and feed efficiencies were similar for summer pigs compared to those in the current study (overall ADG for all breeds of approximately $0.85 \mathrm{~kg}$ and feed:gain of 2.86 averaged across breeds), with performance calculated to be greater than $0.83 \mathrm{~kg} / \mathrm{d}$ and a feed conversion ratio of 2.87 . So, overall, the pigs in the current study performed similarly to other pigs raised in a comparable production system.

Overall no real benefit of one sire breed over another for growth performance was noted in this study, though the average performance was comparable to other hoop systems. Hoop environments could provide pigs with better conditions in specific seasons, and the high-demand niche market for humanely-raised pork means the potential exists for small-scale hog producers to profit using this system (Honeyman et al., 2006). Moreover, in comparison with confinement systems, alternative hoop production systems require far lower capital investments in buildings and equipment, which is a possible way for small-scale hog producers to remain in business.

\section{ACKNOWLEDGEMENT}

This material is based in part upon work supported by the USDA SARE of the Southern Region, Project LS08-211, "A multi-disciplinary approach to improve the environmental performance of niche pork production systems and marketability of Heritage swine breeds." This paper is dedicated to the late Mr. Marty Dudley for his support and hard work on this study.

\section{REFERENCES}

Aziz, N. 2004. Manipulating pork quality through production and pre-slaughter handling. Adv. Pork Prod. 15:245-251.

Casey, D. S. and J. C. M. Dekkers. 2001. Dealing with errors in data from electronic swine feeders. http://www.extension. iastate.edu/ipic/reports/01swinereports/Breedphys01.html

Coffey, M. T., B. G. Diggs, D. L. Handlin, D. A. Knabe, C. V. Maxwell, Jr., P. R. Noland, T. J. Prince and G. L. Gromwell. 1994. Effects of dietary energy during gestation and lactation on reproductive performance of sows: A cooperative study. J. Anim. Sci. 72:4-9.

Cook, R. D. and S. Weisberg. 1982. Residuals and Influence in Regression. London: Chapman and Hall.

Fahmy, M. H. and W. B. Holtman. 1977. Crossbreeding swine in Canada. World review of animal production, vol XIII, 4:9-30.
Gegner, L. 2001. Considerations in organic hog production. ATTRA's Organic Matters Series.

Gegner, L. 2004. Hog production alternatives. ATTRA's Organic Matters Series.

Hasty, J. L., E. van Heugten, M. T. See and D. K. Larick. 2002. Effect of vitamin $\mathrm{E}$ on improving fresh pork quality in Berkshire-sired and Hampshire-sired pigs. J. Anim. Sci. 80:3230-3237.

Honeyman, M. S. 2005. Extensive bedded indoor and outdoor pig production systems in USA: current trends and effects on animal care and product quality. Livest. Prod. Sci. 94:15-24.

Honeyman, M. S. and J. D. Harmon. 2003. Performance of finishing pigs in hoop structures and confinement during winter and summer. J. Anim. Sci. 81:1663-1670.

Honeyman, M. S., R. S. Pirog, G. H. Huber, P. J. Lammers and J. R. Hermann. 2006. The United States pork niche market phenomenon. J. Anim. Sci. 84:2269-2275.

Kleinbeck, S. N. and J. J. McGlone. 1999. Intensive indoor versus outdoor swine production systems: Genotype and supplemental iron effects on blood hemoglobin and selected immune measures in young pigs. J. Anim. Sci. 77:2384-2390.

Lohmann, U., R. Sausen, L. Bengtsson, U. Cubasch, J. Perlwitz, and E. Roeckner. 1993. The Köppen climate classification as a diagnostic tool for general circulation models. Clim. Res. 3:177-193.

McPhee, H. C. 1931. Swine Inbreeding at the United States Department of Agriculture - A Progress Report. J. Anim. Sci. 1:131-134.

Quijandria, B. Jr. and O. W. Robison. 1971. Body weight and backfat deposition in swine: Curves and Correction Factors. J. Anim. Sci. 33:911-918.

Suzuki, K., T. Shibata, H. Kadowaki, H. Abe and T. Toyoshima. 2003. Meat quality comparison of Berkshire, Duroc and crossbred pigs sired by Berkshire and Duroc. Meat Sci. 64:3542.

Talbott, C., T. See, M. Ahmedna, H. Fennell, G. Gunthorp and P. Willis. 2003. Potential for small-scale farmers to produce niche market pork using alternative diets, breeds and rearing environments: Observations from North Carolina. Ren. Ag. Food Sys. 19:135-140.

Taylor, J. M. and L. N. Hazel. 1955. The Growth curve of pigs between 134 and 174 days of age. J. Anim. Sci. 14:1133-1139.

Thornton, K. 1990. Outdoor pig production. Farming Press, Ipswich, UK.

Winters, L. M., R. E. Comstock and D. L. Dailey. 1943. The development of an inbred line of swine (Minn. No. 1) from a Crossbred Foundation. J. Anim. Sci. 2:129-137.

Wood, J. D., G. R. Nute, R. I. Richardson, F. M. Whittington, O. Southwood, G. Plastow, R. Mansbridge, N. da Costa and K. C. Chang. 2004. Effects of breed, diet and muscle on fat deposition and eating quality in pigs. Meat Sci. 67:651-667.

Young, R. J. and A. B. Lawrence. 1994. Feeding behaviour of pigs in groups monitored by a computerized feeding system. Anim. Prod. 58:145-152. 